\title{
Tratamentos utilizados para o controle dos sinais e sintomas na rosácea
}

\author{
Treatments used to control signs and symptoms in rosacea \\ Tratamientos utilizados para controlar los signos y síntomas de la rosácea
}

Recebido: 08/02/2021 | Revisado: 12/02/2021 | Aceito: 21/02/2021 | Publicado: 28/02/2021

\author{
Karla Glazielle Gonçalves dos Santos Malachoski \\ ORCID: https://orcid.org/0000-0002-7910-7585 \\ Universidade Positivo, Brasil \\ E-mail: karlamalachoski@hotmail.com \\ João Luiz Coelho Ribas \\ ORCID: https://orcid.org/0000-0003-0545-5920 \\ Universidade Positivo, Brasil \\ E-mail: jlcribas@yahoo.com.br
}

\begin{abstract}
Resumo
A rosácea é uma patologia inflamatória crônica, que atua de forma progressiva, ou seja, o quadro clínico tende a se agravar com o passar do tempo e com ausência do devido controle terapêutico. Pode ser considerada uma síndrome. Sua etiopatogenia tem como base questões multifatoriais, sendo desencadeada por diversos mecanismos. A rosácea ainda não possui um tratamento curativo e as terapias disponíveis, como antibióticos, corticoides e alguns procedimentos alternativos, atuam no controle dos sinais e sintomas, melhorando as manifestações clínicas. Assim, o objetivo deste trabalho foi analisar, por meio de um levantamento bibliográfico, os tratamentos existentes para os sinais e sintomas da rosácea, bem como os possíveis prejuízos que alguns tratamentos podem causar ao organismo dos indivíduos por ela acometidos. Para fundamentar o presente artigo, foram selecionados 39 artigos, datados de 2004 a 2019 nas bases de dados Surgical and Cosmetic Dermatology, Lilacs, PubMed, Scielo e Google acadêmico. Observou-se que os tratamentos mais tradicionais, como o uso de antibióticos, corticoides e vasoconstritor, podem causar danos ao organismo de forma sistêmica, a exemplo de lesões hepáticas, eventos no trato gastrointestinal e agravamento no quadro de insuficiência vascular. Desta forma os tratamentos alternativos, entre os quais a aplicação toxina botulínica do tipo A possuem um futuro promissor, pois promovem uma resposta satisfatória e com índice de efeitos colaterais muito baixos em comparação aos tratamentos já utilizados.
\end{abstract}

Palavras-chave: Dermatologia; Toxina botulínica tipo A; Rosácea; Antibacterianos; Corticosteroides.

\begin{abstract}
Rosacea is a chronic inflammatory pathology that acts in a progressive manner, that is, the clinical condition tends to worsen over time and with the absence of due therapeutic control. It can be considered a syndrome. Its etiopathogenesis is based on multifactorial issues, being triggered by several mechanisms. Rosacea does not yet have a curative treatment and the available therapies, such as antibiotics, corticosteroids and some alternative procedures, work to control signs and symptoms, improving clinical manifestations. Thus, the objective of this work was to analyze, through a bibliographic survey, the existing treatments for the signs and symptoms of rosacea, as well as the possible damages that some treatments can cause to the organism of the individuals affected by it. To support this article, 39 articles were selected, dated from 2004 to 2019 in the Surgical and Cosmetic Dermatology, Lilacs, PubMed, Scielo and Google academic databases. It was observed that more traditional treatments, such as the use of antibiotics, corticosteroids and brimonidine, can cause systemic damage to the organism, such as liver damage, events in the gastrointestinal tract and worsening of vascular insufficiency. Thus, alternative treatments, including the application of botulinum toxin type A, have a promising future, as they promote a satisfactory response and have a very low side effect index in comparison to the treatments already used.
\end{abstract}

Keywords: Dermatology; Botulinum toxin type A; Rosacea; Anti-bacterial agents; Adrenal cortex hormones.

\section{Resumen}

La rosácea es una patología inflamatoria crónica que actúa de forma progresiva, es decir, el cuadro clínico tiende a empeorar con el tiempo y ante la ausencia del debido control terapéutico. Puede considerarse un síndrome. Su etiopatogenia se basa en cuestiones multifactoriales, desencadenadas por varios mecanismos. La rosácea aún no cuenta con un tratamiento curativo y las terapias disponibles, como antibióticos, corticoides y algunos procedimientos alternativos, funcionan para controlar los signos y síntomas, mejorando las manifestaciones clínicas. Así, el objetivo de este trabajo fue analizar, mediante un relevamiento bibliográfico, los tratamientos existentes para los signos y síntomas de la rosácea, así como los posibles daños que algunos tratamientos pueden ocasionar al organismo de los individuos afectados por ella. Para sustentar este artículo se seleccionaron 39 artículos, fechados de 2004 a 2019 en las bases de datos académicas de Dermatología quirúrgica y cosmética, Lilacs, PubMed, Scielo y Google. Se observó 
que los tratamientos más tradicionales, como el uso de antibióticos, corticoides y brimonidina, pueden causar daño sistémico al organismo, como daño hepático, eventos en el tracto gastrointestinal y agravamiento de la insuficiencia vascular. Así, los tratamientos alternativos, incluida la aplicación de toxina botulínica tipo A, tienen un futuro prometedor, ya que promueven una respuesta satisfactoria y tienen un índice de efectos secundarios muy bajo en comparación con los tratamientos ya utilizados.

Palabras clave: Dermatología; Toxina botulínica tipo A; Rosácea; Antibacterianos; Corticoesteroides.

\section{Introdução}

A rosácea é uma doença vascular da pele, cuja causa é inflamatória e crônica, apresentando vários sintomas clínicos. Inicialmente é caracterizada por pele avermelhada e calor desagradável, causado pela inflamação dos folículos capilares e vasos sanguíneos (Crawford, Pelle, \& James, 2004; Moustafa, Hopkinson, , Huang, \& Feldman, 2015).

A doença afeta cerca de $10 \%$ da população, sendo possível observar uma maior incidência em indivíduos de pele mais clara, do sexo feminino, com maior propensão na faixa etária de 30 a 60 anos e predominando a área convexa da face. Com base em estudos retrospectivos, as taxas atuais variam entre $1,3 \%$ e 2,1\%, provavelmente devido ao fato de que somente os pacientes com sintomas mais graves da doença são incluídos, subnotificando a maioria dos pacientes com sintomas leves (Antonio, Antonio, Trídico, \& Fernandes, 2017; Tan, \& Berg, 2013; Steinhoff, Schmelz, \& Schauber, 2016).

A etiologia é desconhecida, ocorrem reações vasculares aumentadas, causando o desenvolvimento de eritema. Inicialmente apresenta sinais mais brandos que com o passar dos anos sem os devidos cuidados tornam-se mais persistentes e progressivos comprometendo a saúde e bem-estar do portador. A fisiopatologia é multifatorial e ainda não é totalmente compreendida (Crawford et al., 2004; Tan, \& Berg, 2013; Di Matteo, 2019).

Atualmente não há cura e o tratamento busca diminuir os sintomas clínicos e interromper ou retardar a progressão da doença, tornando o diagnóstico precoce importante para isso. Por não haver causa específica, o tratamento é abrangente e pode ser de ação local e sistêmica, visando reduzir a inflamação da pele e aliviar a vermelhidão local. Em algumas situações a região nasal pode apresentar bolhas, edema ou textura granulosa, devido ao processo infiltrativo. Nestes casos há evidências de intervenção cirúrgica, sendo que a incidência no sexo masculino é mais alta do que no sexo feminino (Crawford et al., 2004; Di Matteo, 2019).

Desta forma, este trabalho tem como objetivo realizar uma revisão bibliográfica dos tratamentos existentes para o controle dos sinais e sintomas da rosácea, bem como analisar os possíveis prejuízos que alguns tratamentos podem causar ao organismo dos indivíduos acometidos por tal disfunção.

\section{Metodologia}

Para a realização desse trabalho, foi realizado um levantamento bibliográfico qualitativo (Pereira, et al. 2018). Os artigos e trabalhos para sua execução foram encontrados nas bases de dados Surgical and Cosmetic Dermatology, Lilacs, PubMed, Scielo e Google acadêmico.

Como descritores, foram usados "rosácea", "Toxina botulínica”, "botulínica na rosácea”, "medicamentos para rosácea", "tratamentos alternativos para rosácea". Nos critérios de inclusão foram considerados artigos publicados em revistas científicas (artigos originais, revisões sistemáticas, relatos de experiências, ensaios teóricos, reflexões), obras lançadas entre os anos de 2000 a 2020, em inglês e português.

Foram encontrados no total 130 artigos com base nos descritores e palavras chaves, após a leitura foram selecionados para a execução da pesquisa um total de 39 artigos, o critério de exclusão foram artigos fora do período selecionado e artigos que não continham as informações de relevância com o título e com os objetivos do presente artigo. 


\section{Resultados e Discussão}

Com base nos descritores e palavras-chaves, foram encontradas 130 publicações, das quais, após leitura, selecionou-se 39 para compor este trabalho, por apresentarem informações relevantes e atenderem aos objetivos propostos. As publicações foram organizadas no Quadro 1, de acordo com seu ano de publicação e o conteúdo abordado em cada trabalho, como fisiopatologia, epidemiologia, tratamentos e prejuízos desencadeados aos indivíduos com o uso de medicamentos com ação sistêmica e local.

Quadro 1 - Compilação da pesquisa.

\begin{tabular}{|c|c|c|c|c|}
\hline AUTORES & TÍTULO & ANO & OBJETIVO & CONCLUSÃO \\
\hline $\begin{array}{l}\text { Abram, K. } \\
\text { Silm, H. } \\
\text { Maaroos, H. I. } \\
\text { Oona, M. }\end{array}$ & $\begin{array}{l}\text { Risk factors } \\
\text { associated with } \\
\text { rosacea }\end{array}$ & 2010 & $\begin{array}{l}\text { O objetivo do presente estudo é } \\
\text { avaliar vários fatores de risco } \\
\text { suspeitos de forma coincidente. }\end{array}$ & $\begin{array}{l}\text { A rosácea está principalmente associada à } \\
\text { predisposição familiar. Não há associação } \\
\text { entre infecção por Helicobacter pylori e } \\
\text { rosácea no estudo atual. }\end{array}$ \\
\hline $\begin{array}{l}\text { Augustin, M. } \\
\text { Herberger, K. } \\
\text { Hintzen, S. } \\
\text { Heigel, H. } \\
\text { Franzke, N. } \\
\text { Schäfer, I. }\end{array}$ & $\begin{array}{l}\text { Prevalence of } \\
\text { skin lesions } \\
\text { and need for } \\
\text { treatment in a } \\
\text { cohort of } 90 \\
880 \text { workers }\end{array}$ & 2011 & $\begin{array}{l}\text { Determinação da prevalência de } \\
\text { lesões de pele e da necessidade de } \\
\text { cuidados com base em exames } \\
\text { dermatológicos em adultos } \\
\text { trabalhadores na Alemanha }\end{array}$ & $\begin{array}{l}\text { Lesões dermatológicas e doenças requerem } \\
\text { um maior esclarecimento, pois são } \\
\text { frequentes } 20-30 \% \text { da população Alemã e } \\
\text { indicam alta demanda de tratamento na } \\
\text { população adulta. }\end{array}$ \\
\hline $\begin{array}{l}\text { Awosika, O. } \\
\text { Oussedik, E. }\end{array}$ & $\begin{array}{l}\text { Genetic } \\
\text { predisposition } \\
\text { to rosacea }\end{array}$ & 2018 & $\begin{array}{l}\text { Apresentar os possíveis } \\
\text { mecanismos moleculares da } \\
\text { rosácea com base em estudos } \\
\text { clínicos e laboratoriais recentes. }\end{array}$ & $\begin{array}{l}\text { É necessária uma melhor compreensão dos } \\
\text { mecanismos moleculares da rosácea, pois } \\
\text { dessa forma existirá uma maior compreensão } \\
\text { das complexas ligações em sua } \\
\text { fisiopatologia. Assim, poderá fornecer uma } \\
\text { ponte para opções de tratamento mais } \\
\text { direcionadas e individualizadas aos pacientes } \\
\text { com rosácea. }\end{array}$ \\
\hline $\begin{array}{l}\text { Buhl, T. } \\
\text { Sulk, M. } \\
\text { Nowak, } \\
\text { Buddenkotte, } \\
\begin{array}{l}\text { McDonald, } \\
\text { I. Aubert, }\end{array} \text { J. } \\
\text { Carlavan, I. } \\
\text { Déret, S. } \\
\text { Reiniche, P. } \\
\text { Rivier, M. } \\
\text { Steinhoff, M. } \\
\text { Voegel, J. J. }\end{array}$ & $\begin{array}{l}\text { Molecular and } \\
\text { morphological } \\
\text { characterizatio } \\
\mathrm{n} \text { of } \\
\text { inflammatory } \\
\text { infiltrate in } \\
\text { rosacea reveals } \\
\text { activation of } \\
\text { Th1/Th17 } \\
\text { pathways }\end{array}$ & 2015 & $\begin{array}{l}\text { Caracterizar o } r \text { infiltrado } \\
\text { inflamatório das três rosáceas } \\
\text { cutâneas subtipos de forma } \\
\text { abrangente. }\end{array}$ & $\begin{array}{l}\text { Em conclusão, o estudo mostrou } \\
\text { envolvimento significativo de o sistema } \\
\text { imunológico em todos os subtipos de } \\
\text { rosácea, caracterizando até mesmo a ETR } \\
\text { como uma doença crônica com significativa } \\
\text { inflamação. A resposta da célula T é } \\
\text { dominada por um Th1 / Th17- resposta } \\
\text { imune polarizada, foi verificado a correlação } \\
\text { dos perfis de expressão aprimorados e } \\
\text { coloração para assinatura citocinas incluindo } \\
\text { IFN- } \gamma \text { e IL-17. Expressão de quimiocina } \\
\text { padrões também suportam a polarização Th1 } \\
\text { / Th17 da célula T resposta e recrutamento, } \\
\text { bem como ativação, de macrófagos ou } \\
\text { neutrófilos, que já está presente na ETR e } \\
\text { atinge um máximo em PPR }\end{array}$ \\
\hline $\begin{array}{l}\text { Chamusca, F. V. } \\
\text { Reis, S. R. A. } \\
\text { Lemaire, D. } \\
\text { Medrado, A. P }\end{array}$ & $\begin{array}{l}\text { Mediadores do } \\
\text { efeito } \\
\text { sistêmico do } \\
\text { processo } \\
\text { inflamatório e } \\
\text { terapias } \\
\text { fotobiomodula } \\
\text { doras: uma } \\
\text { revisão de } \\
\text { literatura }\end{array}$ & 2012 & $\begin{array}{l}\text { Documentar e descrever os efeitos } \\
\text { sistêmicos desencadeados pelo } \\
\text { processo inflamatório, } \\
\text { contextualizando-o no âmbito da } \\
\text { cicatrização de ferimentos. }\end{array}$ & $\begin{array}{l}\text { O laser parece estabilizar a resposta } \\
\text { inflamatória e acelerar os eventos iniciais da } \\
\text { inflamação, possibilitando o rápido } \\
\text { estabelecimento dos fenômenos } \\
\text { proliferativos no tecido lesado. }\end{array}$ \\
\hline
\end{tabular}


Research, Society and Development, v. 10, n. 2, e55610212780, 2021

(CC BY 4.0) | ISSN 2525-3409 | DOI: http://dx.doi.org/10.33448/rsd-v10i2.12780

\begin{tabular}{|c|c|c|c|c|}
\hline $\begin{array}{l}\text { Crawford, G. H. } \\
\text { Pelle, M. T. } \\
\text { James, W. D. }\end{array}$ & $\begin{array}{l}\text { Rosacea: I. } \\
\text { Etiology, } \\
\text { pathogenesis, } \\
\text { and subtype } \\
\text { classification }\end{array}$ & 2004 & $\begin{array}{l}\text { Revisar a literatura atual sobre } \\
\text { rosácea, com ênfase no novo } \\
\text { sistema de classificaçãa e nas } \\
\text { principais teorias patogênicas. }\end{array}$ & $\begin{array}{l}\text { Como teorizamos que a patogênese da } \\
\text { rosácea varia com o subtipo fenotípico, } \\
\text { enfatizamos a importância de critérios } \\
\text { claramente definidos e inclusão do subtipo } \\
\text { em estudos futuros. Além disso, as } \\
\text { populações de controle devem ser } \\
\text { devidamente combinadas em termos de } \\
\text { fatores conhecidos por influenciar o fenótipo } \\
\text { da rosácea, como idade, sexo e exposição } \\
\text { cumulativa ao sol. Certamente, muito mais } \\
\text { perguntas do que essas permanecem. Espera- } \\
\text { se que a curiosidade tenha sido estimulada, a } \\
\text { necessidade de pesquisas contínuas } \\
\text { destacada e o progresso em compreender } \\
\text { esta condição comum e importante virá em } \\
\text { seguida. }\end{array}$ \\
\hline Cribier, B. & $\begin{array}{l}\text { Rosacea under } \\
\text { the } \\
\text { microscope: } \\
\text { characteristic } \\
\text { histological } \\
\text { findings }\end{array}$ & 2013 & $\begin{array}{lcr}\text { Discutir } & \text { as } & \text { combinações } \\
\text { específicas } & \text { de } & \text { características } \\
\text { histológicas } & \text { altamente } & \text { sugestivas } \\
\text { de rosácea. } & & \end{array}$ & $\begin{array}{l}\text { A conclusão é que há uma alta taxa de } \\
\text { Demodex transporte em todos os subtipos } \\
\text { clínicos de rosácea. Como o ácaro está } \\
\text { presente em > } 60 \% \text { da rosácea, ele pode ter } \\
\text { um papel na estimulação da inflamação por } \\
\text { meio de suas bactérias ou proteínas } \\
\text { residentes da degradação bacteriana. É } \\
\text { possível que as anormalidades vasculares da } \\
\text { rosácea, principalmente nos capilares, sejam } \\
\text { uma forma de fotodano. A associação entre } \\
\text { alterações vasculares e inflamação } \\
\text { permanece obscura, mas a identificação de } \\
\text { mecanismos pró-inflamatórios da imunidade } \\
\text { inata na rosácea pode ajudar a explicar a } \\
\text { formação de telangiectasia na forma papulo- } \\
\text { pustular da doença. O infiltrado inflamatório } \\
\text { contém principalmente células } \mathrm{T} \text {, } \\
\text { principalmente linfócitos CD4 +. Células } \\
\text { plasmáticas e eosinófilos não são incomuns, } \\
\text { sugerindo uma reação infecciosa. } 5 \text { Esses } \\
\text { marcadores histológicos da rosácea podem } \\
\text { ser bastante úteis para realizar e excluir um } \\
\text { diagnóstico. }\end{array}$ \\
\hline Del Rosso, J. Q. & $\begin{array}{l}\text { Advances in } \\
\text { understanding } \\
\text { and managing } \\
\text { rosacea: part 1: } \\
\text { connecting the } \\
\text { dots between } \\
\text { pathophysiolog } \\
\text { ical } \\
\text { mechanisms } \\
\text { and common } \\
\text { clinical } \\
\text { features of } \\
\text { rosacea with } \\
\text { emphasis on } \\
\text { vascular } \\
\text { changes and } \\
\text { facial } \\
\text { erythema. }\end{array}$ & 2012 & $\begin{array}{l}\text { Ênfase na correlação de } \\
\text { características clínicas e alterações } \\
\text { fisiopatológicas subjacentes nas } \\
\text { apresentações mais comuns de } \\
\text { rosácea encontradas pelo clínico. }\end{array}$ & $\begin{array}{l}\text { Concluiu-se que os mecanismos patogênicos } \\
\text { são modulados pelas terapias disponíveis, e } \\
\text { outros permanecem como alvos para o } \\
\text { desenvolvimento de novos agentes ou } \\
\text { modalidades terapêuticas. }\end{array}$ \\
\hline $\begin{array}{l}\text { Di Matteo, M. C. } \\
\text { Stefano, P. C. } \\
\text { Cirio, A. } \\
\text { López, B. } \\
\text { Centeno, M. }\end{array}$ & $\begin{array}{l}\text { Rosácea } \\
\text { oculocutánea } \\
\text { en un niño }\end{array}$ & 2019 & $\begin{array}{l}\text { Avaliar através do estudo de caso } \\
\text { de um menino de } 1 \text { ano de idade } \\
\text { com rosácea ocular e cutânea que } \\
\text { desenvolveu opacidades corneanas } \\
\text { e deficiência visual. }\end{array}$ & $\begin{array}{l}\text { No caso apresentado, a pouca idade do } \\
\text { paciente e a falta de outras manifestações } \\
\text { cutâneas, como rubor e telangiectasias, } \\
\text { atrasaram o diagnóstico. Deve-se levar em } \\
\text { consideração que, na presença de rosácea } \\
\text { cutânea, a avaliação é essencial, incluindo a }\end{array}$ \\
\hline
\end{tabular}


Research, Society and Development, v. 10, n. 2, e55610212780, 2021

(CC BY 4.0) | ISSN 2525-3409 | DOI: http://dx.doi.org/10.33448/rsd-v10i2.12780

\begin{tabular}{|c|c|c|c|c|}
\hline $\begin{array}{l}\text { Bocian, M. } \\
\text { Cervini, A. B. }\end{array}$ & & & & oftalmologia por se tratar da rosácea ocular. \\
\hline $\begin{array}{l}\text { Draelos, Z. D. } \\
\text { Elewski, B. } \\
\text { Staedtler, G. } \\
\text { Havlickova, B. }\end{array}$ & $\begin{array}{l}\text { Azelaic acid } \\
\text { foam } 15 \% \text { in } \\
\text { the treatment } \\
\text { of } \\
\text { papulopustular } \\
\text { rosacea: a } \\
\text { randomized, } \\
\text { double-blind, } \\
\text { vehicle- } \\
\text { controlled } \\
\text { study }\end{array}$ & 2013 & $\begin{array}{l}\text { Avaliar a eficácia e segurança de } \\
\text { uma nova formulação de espuma } \\
\text { de ácido azelaico (AzA) a } 15 \% \text { de } \\
\text { concentração em comparação com } \\
\text { o veículo sozinho em pacientes } \\
\text { com rosácea papulopustular (PPR). }\end{array}$ & $\begin{array}{l}\text { Os resultados indicaram que a nova } \\
\text { formulação de espuma de AzA é eficaz e } \\
\text { bem tolerada em uma população de } \\
\text { pacientes com PPR. Embora nenhuma } \\
\text { formulação única seja apropriada para todos } \\
\text { os pacientes, o desenvolvimento de uma } \\
\text { nova formulação de espuma, além de outros } \\
\text { veículos disponíveis, oferece opções aos } \\
\text { pacientes e permite que os profissionais de } \\
\text { saúde correspondam às necessidades, bem } \\
\text { como às preferências de pacientes } \\
\text { individuais e tipos de pele com modalidades } \\
\text { de entrega adequadas }\end{array}$ \\
\hline $\begin{array}{l}\text { Duman, N. } \\
\text { Ersoy Evans, S. } \\
\text { Atakan, N. }\end{array}$ & $\begin{array}{l}\text { Rosacea and } \\
\text { cardiovascular } \\
\text { risk factors: a } \\
\text { case control } \\
\text { study }\end{array}$ & 2014 & $\begin{array}{lcr}\text { Investigar o risco de } & \text { doença } \\
\text { cardiovascular } & \text { (DCV) } & \text { em } \\
\text { pacientes com rosácea. } & \end{array}$ & $\begin{array}{l}\text { Pacientes com rosácea podem ter um alto } \\
\text { risco de DCV. Como tal, recomenda-se um } \\
\text { acompanhamento rigoroso dos pacientes } \\
\text { com rosácea devido ao aumento do risco de } \\
\text { DCV. O mecanismo subjacente a este risco } \\
\text { aumentado é desconhecido, e estudos } \\
\text { adicionais randomizados e controlados são } \\
\text { necessários para esclarecimento. }\end{array}$ \\
\hline $\begin{array}{l}\text { Feldman, S. R. } \\
\text { Huang, W. W. } \\
\text { Huynh, T. T. }\end{array}$ & $\begin{array}{l}\text { Current drug } \\
\text { therapies for } \\
\text { rosacea: a } \\
\text { chronic } \\
\text { vascular and } \\
\text { inflammatory } \\
\text { skin disease }\end{array}$ & 2014 & $\begin{array}{l}\text { Discutir a evolução da } \\
\text { fisiopatologia da rosácea, os } \\
\text { fatores envolvidos na promoção } \\
\text { das anormalidades vasculares e } \\
\text { inflamatórias crônicas observadas } \\
\text { na rosácea e as terapias } \\
\text { medicamentosas disponíveis para a } \\
\text { doença }\end{array}$ & $\begin{array}{l}\text { A rosácea é uma doença inflamatória e } \\
\text { vascular crônica da pele. Embora a } \\
\text { fisiopatologia da rosácea ainda seja pouco } \\
\text { compreendida, fatores subjacentes que } \\
\text { desempenham um papel na patogênese da } \\
\text { rosácea foram identificados. Fatores que } \\
\text { promovem anormalidades vasculares e } \\
\text { inflamatórias crônicas afetam a } \\
\text { fisiopatologia em evolução da rosácea. } \\
\text { Portanto, compreender o papel dos fatores } \\
\text { que desencadeiam o início dos sintomas da } \\
\text { rosácea e agravar a condição é crucial no } \\
\text { tratamento desta doença de pele. }\end{array}$ \\
\hline $\begin{array}{l}\text { Fowler Jr, J. } \\
\text { Jackson, M. } \\
\text { Moore, A. } \\
\text { Jarratt, M. } \\
\text { Jones, T. } \\
\text { Meadows, K. } \\
\text { Steinhoff, M. } \\
\text { Rudisill, D. } \\
\text { Leoni, M. }\end{array}$ & $\begin{array}{l}\text { Efficacy and } \\
\text { safety of once- } \\
\text { daily topical } \\
\text { brimonidine } \\
\text { tartrate gel } \\
0.5 \% \text { for the } \\
\text { treatment of } \\
\text { moderate to } \\
\text { severe facial } \\
\text { erythema of } \\
\text { rosacea: results } \\
\text { of two } \\
\text { randomized, } \\
\text { double-blind, } \\
\text { and vehicle- } \\
\text { controlled } \\
\text { pivotal studies }\end{array}$ & 2013 & $\begin{array}{l}\text { Avaliar a eficácia e segurança do } \\
\text { gel tópico de tartarato de } \\
\text { brimonidina a0,5\% para o } \\
\text { tratamento do eritema da rosácea. }\end{array}$ & $\begin{array}{l}\text { O gel tópico de tartarato de brimonidina } \\
0,5 \% \text { foi significativamente mais eficaz do } \\
\text { que o gel veículo ao longo de } 12 \text { horas nos } \\
\text { dias } 1,15 \text { e } 29 \text {, com diferença significativa } \\
\text { observada tão cedo quanto } 30 \text { minutos após } \\
\text { a primeira aplicação no dia } 1 \text { (todos } \\
\text { p }<0,001 \text { ). Não foram observados } \\
\text { taquifilaxia, rebote ou agravamento de } \\
\text { outros sinais de doença. A incidência } \\
\text { ligeiramente maior de eventos adversos foi } \\
\text { observada para o tratamento em relação ao } \\
\text { veículo; no entanto, a maioria dos eventos } \\
\text { adversos foram dermatológicos, leves e de } \\
\text { natureza transitória. }\end{array}$ \\
\hline $\begin{array}{l}\text { Kim, J. Y. } \\
\text { Kim, Y. J. } \\
\text { Lim, B. J. } \\
\text { Sohn, H. J. } \\
\text { Shin, D. } \\
\text { Oh, S. H. }\end{array}$ & $\begin{array}{l}\text { Increased } \\
\text { expression of } \\
\text { cathelicidin by } \\
\text { direct } \\
\text { activation of } \\
\text { protease- } \\
\text { activated } \\
\text { receptor } \quad 2 \text { : }\end{array}$ & 2014 & $\begin{array}{l}\text { Determinar a relação entre a } \\
\text { expressão da protéase do tipo } 2 \\
\text { (PAR-2) e catelicidina na rosácea e } \\
\text { testar o efeito da ativação direta de } \\
\text { PAR-2 na expressão de catelicidina } \\
\text { em queratinócitos. }\end{array}$ & $\begin{array}{l}\text { O PAR-2 pode participar na patogênese da } \\
\text { rosácea por meio da ativação da catelicidina } \\
\text { LL-37, um mediador das respostas imunes } \\
\text { inatas na pele. }\end{array}$ \\
\hline
\end{tabular}


Research, Society and Development, v. 10, n. 2, e55610212780, 2021

(CC BY 4.0) | ISSN 2525-3409 | DOI: http://dx.doi.org/10.33448/rsd-v10i2.12780

\begin{tabular}{|c|c|c|c|c|}
\hline & $\begin{array}{l}\text { possible } \\
\text { implications on } \\
\text { the } \\
\text { pathogenesis of } \\
\text { rosacea }\end{array}$ & & & \\
\hline $\begin{array}{l}\text { Korting, H. C. } \\
\text { Schöllmann, C. }\end{array}$ & $\begin{array}{l}\text { Current topical } \\
\text { and systemic } \\
\text { approaches to } \\
\text { treatment of } \\
\text { rosacea }\end{array}$ & 2009 & $\begin{array}{l}\text { Avaliar os regimes terapêuticos } \\
\text { mais comumente usados e mais } \\
\text { estabelecidos nos sinais e sintomas } \\
\text { da rosácea. }\end{array}$ & $\begin{array}{l}\text { Existe uma série de opções de terapia tópica } \\
\text { e sistêmica para a rosácea, especialmente } \\
\text { para o subtipo papulopustular. Muitas dessas } \\
\text { opções já existem há décadas. No entanto, } \\
\text { evidências suficientes com relação à eficácia } \\
\text { e tolerabilidade existem apenas para alguns } \\
\text { dos ingredientes farmacológicos ativos e } \\
\text { tratamentos usados. }\end{array}$ \\
\hline $\begin{array}{l}\text { Lanoue, J. } \\
\text { Goldenberg, G. }\end{array}$ & $\begin{array}{l}\text { Therapies to } \\
\text { improve the } \\
\text { cosmetic } \\
\text { symptoms of } \\
\text { rosacea }\end{array}$ & 2015 & $\begin{array}{l}\text { Revisar os tratamentos cosméticos } \\
\text { existentes e emergentes para a } \\
\text { rosácea, incluindo medicamentos } \\
\text { tópicos, terapias farmacológicas } \\
\text { sistêmicas, modalidades à base de } \\
\text { luz e intervenções procedimentais, } \\
\text { e avaliar sua capacidade de } \\
\text { melhorar os sintomas cosméticos } \\
\text { da rosácea. }\end{array}$ & $\begin{array}{l}\text { Embora avanços recentes em farmacologia e } \\
\text { a tecnologia a laser tenha fornecido aos } \\
\text { médicos modalidades de tratamento novas e } \\
\text { eficazes para rosácea, permanece uma } \\
\text { doença mal compreendida sem uma cura } \\
\text { definitiva. O impacto negativo da rosácea na } \\
\text { qualidade de vida dos pacientes pode ser } \\
\text { substancial, mas a gestão eficaz dos } \\
\text { sintomas cosméticos pode minimizar esses } \\
\text { efeitos deletérios. A terapia deveria ser } \\
\text { individualizada e direcionada ao tratamento } \\
\text { dos sintomas que mais incomodam o } \\
\text { paciente. Além disso, o tratamento eficaz } \\
\text { frequentemente exigirá uma combinação de } \\
\text { modalidades ou terapias sequenciais para } \\
\text { alcançar resultados cosméticos ideais. }\end{array}$ \\
\hline $\begin{array}{l}\text { Marques, R. Z. } \\
\text { Moran, D. K. S. } \\
\text { Speyer, C. } \\
\text { Azevedo, L. C. } \\
\text { Cohen, S. }\end{array}$ & $\begin{array}{l}\text { Tratamento de } \\
\text { rosácea com } \\
\text { duas faixas de } \\
\text { comprimento } \\
\text { de onda de luz } \\
\text { intensa pulsada } \\
\text { num mesmo } \\
\text { disparo }\end{array}$ & 2016 & $\begin{array}{l}\text { Avaliar a melhora clínica e } \\
\text { dermatoscópica do eritema facial e } \\
\text { rubor, e o clareamento dos vasos à } \\
\text { dermatoscopia após o uso de luz } \\
\text { intensa pulsada. }\end{array}$ & $\begin{array}{l}\text { Até o momento nenhum tratamento mostrou- } \\
\text { se completo para a rosácea telangiectásica. } \\
\text { Este estudo demonstrou que o tratamento } \\
\text { com luz intensa pulsada utilizando a } \\
\text { tecnologia dual band é eficaz no tratamento } \\
\text { da rosácea. }\end{array}$ \\
\hline Melnik, B. C. & $\begin{array}{l}\text { Rosacea: the } \\
\text { blessing of the } \\
\text { Celts-an } \\
\text { approach to } \\
\text { pathogenesis } \\
\text { through } \\
\text { translational } \\
\text { research }\end{array}$ & 2016 & $\begin{array}{l}\text { Apresentar um novo e unificador } \\
\text { conceito de patogênese da rosácea } \\
\text { com foco no aumento da } \\
\text { responsividade ao estresse do } \\
\text { retículo endoplasmático (ER), que } \\
\text { é mediado por meio de } \\
\text { esfingosina-1-fosfato aprimorado } \\
\text { (S1P) na qual indica uma das } \\
\text { sinalizações na pele com rosácea. }\end{array}$ & $\begin{array}{l}\text { A evidência translacional apresentada lança } \\
\text { uma nova luz na patogênese da rosácea } \\
\text { induzida pelo estresse por ER. Este conceito } \\
\text { unificador explica a patologia molecular de } \\
\text { rosácea, a atividade promotora de doenças } \\
\text { dos gatilhos clínicos da rosácea e a } \\
\text { contração correspondente de medicamentos } \\
\text { anti-rosácea. }\end{array}$ \\
\hline $\begin{array}{l}\text { Moore, A. } \\
\text { Kempers, S. } \\
\text { Murakawa, G. } \\
\text { Weiss, J. } \\
\text { Tauscher, A. } \\
\text { Swinyer, L. } \\
\text { Liu, H. } \\
\text { Leoni, M. }\end{array}$ & $\begin{array}{l}\text { Long-term } \\
\text { safety and } \\
\text { efficacy of } \\
\text { once-daily } \\
\text { topical } \\
\text { brimonidine } \\
\text { tartrate gel } \\
0.5 \% \text { for the } \\
\text { treatment of } \\
\text { moderate to } \\
\text { severe facial } \\
\text { erythema of } \\
\text { rosacea: results } \\
\text { of a 1-year } \\
\text { open-label }\end{array}$ & 2014 & $\begin{array}{l}\text { Avaliar a segurança e eficácia do } \\
\text { gel de brimonidina (BT) tópico } \\
0,5 \% \text { quando o medicamento é } \\
\text { aplicado uma vez ao dia por até } 12 \\
\text { meses, nos pacientes acometidos } \\
\text { pela rosácea. }\end{array}$ & $\begin{array}{l}\text { Os resultados demonstraram que o gel BT } \\
\text { tópico 0,5\% proporcionou eficácia } \\
\text { significativamente maior e um início de ação } \\
\text { mais rápido em comparação com o gel } \\
\text { veículo, com um bom perfil de segurança } \\
\text { geral, para pacientes com eritema moderado } \\
\text { a severo na rosácea. }\end{array}$ \\
\hline
\end{tabular}


Research, Society and Development, v. 10, n. 2, e55610212780, 2021

(CC BY 4.0) | ISSN 2525-3409 | DOI: http://dx.doi.org/10.33448/rsd-v10i2.12780

\begin{tabular}{|c|c|c|c|c|}
\hline & study & & & \\
\hline $\begin{array}{l}\text { Moustafa, F. } \\
\text { Hopkinson, D. } \\
\text { Huang, K. E. } \\
\text { Feldman, S. }\end{array}$ & $\begin{array}{ll}\text { Prevalence } & \text { of } \\
\text { rosacea } & \text { in } \\
\text { community } & \\
\text { settings } & \end{array}$ & 2015 & $\begin{array}{l}\text { Avaliar a prevalência da rosácea } \\
\text { em ambientes comunitários, como } \\
\text { shopping, o Departamento de } \\
\text { Veículos Motorizados e mercearia }\end{array}$ & $\begin{array}{l}\text { Com base na observação direta de } \\
\text { indivíduos em ambientes comunitários, a } \\
\text { rosácea é mais comum do que relatado } \\
\text { anteriormente nos Estados Unidos. } \\
\text { Ao sugerir que a prevalência da rosácea é } \\
\text { subestimada nas comunidades dos Estados } \\
\text { Unidos, este estudo foi importante para criar } \\
\text { uma base para a qual outro trabalho pode ser } \\
\text { feito e assim avaliar melhor a prevalência } \\
\text { desta condição entre as comunidades. Como } \\
\text { a rosácea é uma doença crônica e } \\
\text { progressiva, uma melhor compreensão pode } \\
\text { criar consciência, levando os pacientes a um } \\
\text { tratamento mais rápido e melhores } \\
\text { resultados. }\end{array}$ \\
\hline $\begin{array}{l}\text { Okhovat, J. P. } \\
\text { Armstrong, A. }\end{array}$ & $\begin{array}{l}\text { Updates in } \\
\text { rosacea: } \\
\text { epidemiology, } \\
\text { risk factors, } \\
\text { and } \\
\text { management } \\
\text { strategies }\end{array}$ & 2014 & $\begin{array}{l}\text { Discutir as atualizações na } \\
\text { epidemiologia, fatores de risco e } \\
\text { estratégias de manejo para rosácea }\end{array}$ & $\begin{array}{l}\text { A rosácea continua sendo uma doença } \\
\text { inflamatória crônica da pele comum. } \\
\text { Pesquisas em andamento tentam } \\
\text { compreender a patogênese e os fatores de } \\
\text { risco da rosácea. Exposição à radiação UV, } \\
\text { desregulação neuro-humoral imunológica e } \\
\text { agentes infecciosos, como Demodex têm } \\
\text { sido implicados na patogênese exacerbação } \\
\text { da rosácea. Tratamentos incluindo } \\
\text { antibióticos tópicos e sistêmicos, ácido } \\
\text { azelaico e mais novos } \alpha-2 \text { agonistas } \\
\text { forneceram aos pacientes opções } \\
\text { terapêuticas crescentes. Mais pesquisas são } \\
\text { necessárias para elucidar os mecanismos } \\
\text { específicos subjacentes a esta doença de pele } \\
\text { comum, mas pouco compreendida. }\end{array}$ \\
\hline $\begin{array}{l}\text { Reinholz, M. } \\
\text { Ruzicka, T. } \\
\text { Schauber, J. }\end{array}$ & $\begin{array}{l}\text { Cathelicidin } \\
\text { LL-37: an } \\
\text { antimicrobial } \\
\text { peptide with a } \\
\text { role in } \\
\text { inflammatory } \\
\text { skin disease }\end{array}$ & 2012 & $\begin{array}{l}\text { Delinear as evidências atuais sobre } \\
\text { o papel da catelicidina LL-37 na } \\
\text { patogênese das doenças } \\
\text { inflamatórias da pele }\end{array}$ & $\begin{array}{l}\text { Catelicidina LL-37 é um AMP (peptídeo } \\
\text { antimicrobiano) importante encontrado em } \\
\text { pele. O AMP está envolvido na patogênese } \\
\text { de doenças inflamatórias crônicas da pele. À } \\
\text { medida que os mecanismos regulatórios do } \\
\text { gene da catelicidina e do processamento de } \\
\text { peptídeos ocorrem, surgem estratégias mais } \\
\text { claras para influenciar os processos } \\
\text { inflamatórios. Além disso, as terapias } \\
\text { estabelecidas, como medicamentos tópicos e } \\
\text { tratamentos sistêmicos para rosácea ou } \\
\text { psoríase podem mediar seus efeitos por meio } \\
\text { de seu impacto na catelicidina. }\end{array}$ \\
\hline $\begin{array}{l}\text { Schaller, M. } \\
\text { Almeida, L. M. } \\
\text { Bewley, A. } \\
\text { Cribier, B. } \\
\text { Dlova, N. C. } \\
\text { Kautz, G. } \\
\text { Mannis, M. } \\
\text { Oon, H. H. } \\
\text { Rajagopalan, M. } \\
\text { Steinhoff, M. } \\
\text { Troielli, P. } \\
\text { Webster, P. } \\
\text { Wu, G. Y. }\end{array}$ & $\begin{array}{l}\text { Rosacea } \\
\text { treatment } \\
\text { update: } \\
\text { recommendatio } \\
\text { ns from the } \\
\text { global } \\
\text { ROSacea } \\
\text { COnsensus } \\
\text { (ROSCO) } \\
\text { panel }\end{array}$ & 2017 & $\begin{array}{l}\text { Incorporar as melhores evidências } \\
\text { de tratamento atuais com } \\
\text { experiência clínica de um painel } \\
\text { internacional de especialistas e } \\
\text { estabelecer consenso para } \\
\text { melhorar os resultados para } \\
\text { pacientes com rosácea }\end{array}$ & $\begin{array}{l}\text { O diagnóstico e o tratamento da rosácea } \\
\text { devem ser baseados na apresentação clínica. } \\
\text { O consenso foi alcançado para apoiar esta } \\
\text { abordagem para estratégias de tratamento da } \\
\text { rosácea, com a utilização de antibióticos } \\
\text { orais. }\end{array}$ \\
\hline
\end{tabular}


Research, Society and Development, v. 10, n. 2, e55610212780, 2021

(CC BY 4.0) | ISSN 2525-3409 | DOI: http://dx.doi.org/10.33448/rsd-v10i2.12780

\begin{tabular}{|c|c|c|c|c|}
\hline $\begin{array}{l}\text { van Zuuren, E. } \\
\text { Tan, J. } \\
\text { Thiboutot, D. }\end{array}$ & & & & \\
\hline $\begin{array}{l}\text { Steinhoff, M. } \\
\text { Schauber, J. } \\
\text { Leyden, J. J. }\end{array}$ & $\begin{array}{l}\text { New insights } \\
\text { into rosacea } \\
\text { pathophysiolog } \\
\text { y: a review of } \\
\text { recent findings }\end{array}$ & 2013 & $\begin{array}{lrr}\text { Discutir algumas das descobertas } \\
\text { recentes e } & \text { construir } & \text { hipóteses } \\
\text { unificadoras } & \text { para } & \text { uma } \\
\text { compreensão } & \text { moderna } & \text { da } \\
\text { fisiopatologia da rosácea. } & \end{array}$ & $\begin{array}{l}\text { Mais trabalhos precisam ser feitos para } \\
\text { entender a complexa rede desregulada de } \\
\text { células e mediadores dacrosácea. A pesquisa } \\
\text { atual com foco nas causas subjacentes da } \\
\text { rosácea aponta para uma predisposição } \\
\text { genética e certos fatores desencadeantes que } \\
\text { ajudam a estabelecer o sintoma de rubor, a } \\
\text { manifestação clínica inicial usual da rosácea. } \\
\text { Pesquisas futuras precisam abordar a } \\
\text { comunicação entre o sistema nervoso da pele } \\
\text { e o sistema imunológico inato (em relação à } \\
\text { ativação e inibição), e o controle da ativação } \\
\text { dos fibroblastos, bem como as } \\
\text { consequências da ativação dos } \\
\text { queratinócitos. }\end{array}$ \\
\hline $\begin{array}{l}\text { Steinhoff, M. } \\
\text { Schmelz, M. } \\
\text { Schauber, J. }\end{array}$ & $\begin{array}{l}\text { Facial } \\
\text { erythema of } \\
\text { rosacea- } \\
\text { aetiology, } \\
\text { different } \\
\text { pathophysiolog } \\
\text { ies and } \\
\text { treatment } \\
\text { options }\end{array}$ & 2016 & $\begin{array}{l}\text { Discutir as causas potenciais, as } \\
\text { diferentes fisiopatologias e as } \\
\text { opções de tratamento atuais para } \\
\text { atender às necessidades médicas } \\
\text { não atendidas de pacientes com } \\
\text { eritema facial de rosácea. }\end{array}$ & $\begin{array}{l}\text { Embora as causas precisas dos diferentes } \\
\text { subtipos de eritema em pacientes com } \\
\text { rosácea e suas patofisiologias ainda sejam } \\
\text { um tópico de investigação e possam variar } \\
\text { entre os pacientes, os achados mais } \\
\text { consistentes em pacientes com rosácea são } \\
\text { anormalidade vascular e eritema facial. A } \\
\text { adição bem-vinda de tartarato de } \\
\text { brimonidina ao arsenal de tratamentos para } \\
\text { rosácea pode oferecer alívio dos sintomas de } \\
\text { eritema facial. Estudos recentes de longo } \\
\text { prazo mostraram que o gel tópico de } \\
\text { brimonidina } 0,33 \% \text { é seguro, bem tolerado e } \\
\text { eficaz para o tratamento de eritema } \\
\text { transitório e persistente em pacientes com } \\
\text { rosácea. Estudos futuros precisarão } \\
\text { demonstrar eficácia adicional para eritema } \\
\text { facial (não associado a pápula ou pústula), } \\
\text { que pode ser observado em todos os subtipos } \\
\text { de rosácea. }\end{array}$ \\
\hline $\begin{array}{l}\text { Tan, J. } \\
\text { Berg, M. }\end{array}$ & $\begin{array}{l}\text { Rosacea: } \\
\text { current state of } \\
\text { epidemiology }\end{array}$ & 2013 & $\begin{array}{llr}\text { Fornecer uma } & \text { perspectiva } \\
\text { atualizada sobre o estado atual da } \\
\text { epidemiologia da } & \text { rosácea e sua } \\
\text { distribuição } & \text { e } & \text { determinantes } \\
\text { potenciais. } & & \end{array}$ & $\begin{array}{l}\text { Embora a prevalência de rosácea pareça ser } \\
\text { maior em pessoas com fototipos mais claros, } \\
\text { isso pode ser resultado de viés de } \\
\text { notificação, visto que esses estudos foram } \\
\text { realizados no norte da Europa. No geral, } \\
\text { Exploração continuada de associações } \\
\text { potenciais de rosácea com microrganismos, } \\
\text { como Demodex, B oleronius, S epidermidis, } \\
\text { e H pylori pode fornecer mais informações } \\
\text { sobre a causa da imunidade inata regulação } \\
\text { ascendente do sistema na rosácea. }\end{array}$ \\
\hline $\begin{array}{l}\text { Trindade Neto, P. } \\
\text { Rocha, K. B. F. } \\
\text { Lima, J. B. D. } \\
\text { Nunes, J. C. S. } \\
\text { Silva, A. C. D. }\end{array}$ & $\begin{array}{l}\text { Rosácea } \\
\text { granulomatosa: } \\
\text { relato de caso - } \\
\text { enfoque } \\
\text { terapêutico }\end{array}$ & 2006 & $\begin{array}{l}\text { Relatar um caso de rosácea } \\
\text { granulomatosa, em } \\
\text { sexo masculino, } 39 \text { anos, tratado } \\
\text { com limeciclina oral e } \\
\text { metronidazol tópico. }\end{array}$ & $\begin{array}{l}\text { Baseados nesse estudo, os autores } \\
\text { conduziram o tratamento do paciente em } \\
\text { questão com a associação de antibiótico oral, } \\
\text { limeciclina e metronidazol tópico até a } \\
\text { melhora satisfatória do quadro clínico e, em } \\
\text { seguida, mantiveram o uso isolado do gel de } \\
\text { metronidazol, com remissão do quadro. }\end{array}$ \\
\hline $\begin{array}{l}\text { Two, A. M. } \\
\text { Del Rosso, J. Q. }\end{array}$ & $\begin{array}{l}\text { Kallikrein } 5- \\
\text { mediated } \\
\text { inflammation } \\
\text { in rosacea: } \\
\text { clinically }\end{array}$ & 2014 & $\begin{array}{l}\text { Revisar a literatura que apoia o } \\
\text { papel da calicreína } 5 \text { na } \\
\text { fisiopatologia da rosácea. }\end{array}$ & $\begin{array}{l}\text { Os inibidores diretos e indiretos da calicreína } \\
\text { tissular 5 (KLK5), incluindo AzA e } \\
\text { doxiciclina, demonstraram suprimir tanto a } \\
\text { fisiopatologia subjacente quanto as } \\
\text { manifestações clínicas da rosácea. }\end{array}$ \\
\hline
\end{tabular}




\begin{tabular}{|c|c|c|c|c|}
\hline & $\begin{array}{l}\text { relevant } \\
\text { correlations } \\
\text { with acute and } \\
\text { chronic } \\
\text { manifestations } \\
\text { in rosacea and } \\
\text { how individual } \\
\text { treatments may } \\
\text { provide } \\
\text { therapeutic } \\
\text { benefit }\end{array}$ & & & \\
\hline $\begin{array}{l}\text { Two, A. M. } \\
\text { Wu, W. } \\
\text { Gallo, R. L. } \\
\text { Hata, T. R. }\end{array}$ & $\begin{array}{l}\text { Rosacea: part I. } \\
\text { Introduction, } \\
\text { categorization, } \\
\text { histology, } \\
\text { pathogenesis, } \\
\text { and risk factors }\end{array}$ & 2015 & $\begin{array}{l}\text { Descrever os diferentes subtipos de } \\
\text { rosácea, incluindo os sintomas } \\
\text { típicos e achados fenotípicos em } \\
\text { cada um dos subtipos; descrever } \\
\text { em detalhes a patogênese } \\
\text { molecular por trás da rosácea, } \\
\text { incluindo o papel dos } \\
\text { microrganismos, o sistema } \\
\text { imunológico inato e desregulação } \\
\text { neuronal; e compreender as } \\
\text { comorbidades mais comumente } \\
\text { vistas em pacientes com rosácea. }\end{array}$ & $\begin{array}{l}\text { Em conclusão, a rosácea é uma doença } \\
\text { inflamatória crônica que afeta a pele } \\
\text { principalmente da parte central da face. } \\
\text { Quatro subtipos principais de rosácea são } \\
\text { reconhecidos, todos geralmente } \\
\text { diagnosticados clinicamente. Embora a } \\
\text { causa da rosácea permaneça obscura, a } \\
\text { desregulação dos sistemas imune inato e } \\
\text { adaptativo e do sistema nervoso parecem } \\
\text { contribuir para sua patogênese, levando à } \\
\text { hipersensibilidade da pele em resposta a } \\
\text { gatilhos ambientais comuns. }\end{array}$ \\
\hline $\begin{array}{l}\text { Two, A. M. } \\
\text { Wu, W. } \\
\text { Gallo, R. L. } \\
\text { Hata, T. R. }\end{array}$ & $\begin{array}{l}\text { Rosacea: part } \\
\text { II. Topical and } \\
\text { systemic } \\
\text { therapies in the } \\
\text { treatment of } \\
\text { rosacea }\end{array}$ & 2015 & $\begin{array}{l}\text { Desenvolver um plano de } \\
\text { tratamento para rosácea usando } \\
\text { uma abordagem baseada em } \\
\text { sintomas; descrever a eficácia, } \\
\text { segurança e mecanismo de ação } \\
\text { das terapias atuais da rosácea; e } \\
\text { identificar tratamentos emergentes } \\
\text { para rosácea. }\end{array}$ & $\begin{array}{l}\text { A educação do paciente, cuidados com a } \\
\text { pele e tratamentos farmacológicos são todos } \\
\text { os pilares de uma abordagem eficaz e } \\
\text { abrangente manejo da rosácea. Com os } \\
\text { avanços recentes na compreensão da } \\
\text { patogênese da rosácea, mais oportunidades } \\
\text { para intervenções terapêuticas estão sendo } \\
\text { descobertas. Além dos efeitos anti- } \\
\text { inflamatórios e antioxidantes dos } \\
\text { medicamentos tópicos e sistêmicos atuais, } \\
\text { novas terapias, como inibidores de serina } \\
\text { protease e estabilizadores de mastócitos, } \\
\text { também podem melhorar os sintomas da } \\
\text { rosácea. A abordagem de novos tratamentos, } \\
\text { com foco na educação do paciente e no } \\
\text { cuidado da pele, pode permitir um melhor } \\
\text { controle dos sintomas e uma melhor } \\
\text { qualidade de vida para os indivíduos com } \\
\text { rosácea. }\end{array}$ \\
\hline $\begin{array}{l}\text { Weinkle, A. P. } \\
\text { Doktor, V. } \\
\text { Emer, J. }\end{array}$ & $\begin{array}{l}\text { Update on the } \\
\text { management of } \\
\text { rosacea }\end{array}$ & 2015 & $\begin{array}{l}\text { Descrever tratamentos atualmente } \\
\text { disponíveis e estabelecer opiniões } \\
\text { sobre terapias emergentes e } \\
\text { combinadas }\end{array}$ & $\begin{array}{l}\text { A chave fundamental para o manejo bem- } \\
\text { sucedido da rosácea é baseada na } \\
\text { identificação do subtipo específico, } \\
\text { compreendendo a gravidade da apresentação } \\
\text { e tratamentos personalizados para melhor } \\
\text { atender às expectativas do paciente. Pesquisa } \\
\text { contínua em cosméticos e os aspectos } \\
\text { médicos desta condição irão definir melhor } \\
\text { os protocolos de tratamento que acabarão } \\
\text { por refinar as atuais opções disponíveis para } \\
\text { os pacientes. }\end{array}$ \\
\hline $\begin{array}{l}\text { Wilkin, J. } \\
\text { Dahl, M. } \\
\text { Detmar, M. } \\
\text { Drake, L. } \\
\text { Liang, M. H. } \\
\text { Odom, R. } \\
\text { Powell, F. }\end{array}$ & $\begin{array}{l}\text { Standard } \\
\text { grading system } \\
\text { for rosacea: } \\
\text { report of the } \\
\text { National } \\
\text { Rosacea } \\
\text { Society Expert } \\
\text { Committee on } \\
\text { the } \\
\text { classification }\end{array}$ & 2004 & $\begin{array}{l}\text { Este instrumento investigacional se } \\
\text { destina a fornecer uma base para } \\
\text { uma melhor compreensão da } \\
\text { rosácea entre os profissionais e } \\
\text { pesquisadores. Estabelecendo uma } \\
\text { linguagem comum para } \\
\text { comunicação facilitando o } \\
\text { desenvolvimento da abordagem até } \\
\text { o diagnóstico e tratamento. }\end{array}$ & $\begin{array}{l}\text { Ao desenvolver um sistema de classificação } \\
\text { padrão para rosácea, o comitê tentou projetar } \\
\text { um sistema básico para processamento de } \\
\text { exame de forma prática, útil e semelhantes } \\
\text { aos exames usuais atualmente realizados na } \\
\text { prática clínica. Para ajudar os médicos na } \\
\text { avaliação de seus pacientes, o comitê } \\
\text { desenvolveu um fluxograma de diagnóstico } \\
\text { padrão. Sobrepostos a este sistema padrão } \\
\text { básico, os pesquisadores são encorajados a }\end{array}$ \\
\hline
\end{tabular}




\begin{tabular}{|c|c|c|c|c|}
\hline & $\begin{array}{l}\text { and staging of } \\
\text { rosacea }\end{array}$ & & & $\begin{array}{l}\text { estudar e explorar recursos além o mínimo, } \\
\text { usando sistemas mais sensíveis e } \\
\text { reproduzíveis e aplicando novas tecnologias } \\
\text { e metodologias que podem promover ainda } \\
\text { mais o conhecimento científico da rosácea. }\end{array}$ \\
\hline $\begin{array}{l}\text { Antonio, C. R. } \\
\text { Antonio, J. R. } \\
\text { Trídico, L. A. } \\
\text { Fernandes, T. É. }\end{array}$ & $\begin{array}{l}\text { Tratamento de } \\
\text { rosácea com } \\
\text { toxina } \\
\text { botulínica }\end{array}$ & 2017 & $\begin{array}{l}\text { Avaliar a ação da toxina botulínica } \\
\text { no tratamento da rosácea } \\
\text { persistente e refratária a diversos } \\
\text { tratamentos clínicos }\end{array}$ & $\begin{array}{l}\text { A toxina botulínica tem se mostrado nova } \\
\text { opção terapêutica para o tratamento de } \\
\text { rosácea que trouxe satisfação e melhora na } \\
\text { qualidade de vida da paciente do caso } \\
\text { relatado }\end{array}$ \\
\hline $\begin{array}{l}\text { Park, K. Y. } \\
\text { Hyun, M. Y. } \\
\text { Jeong, S. Y. } \\
\text { Kim, B. J. } \\
\text { Kim, M. N. } \\
\text { Hong, C. K. }\end{array}$ & $\begin{array}{l}\text { Botulinum } \\
\text { toxin for the } \\
\text { treatment of } \\
\text { refractory } \\
\text { erythema and } \\
\text { flushing } \\
\text { rosacea }\end{array}$ & 2015 & $\begin{array}{lccc}\text { Relatar dois } & \text { casos } & \text { de } & \text { eritema } \\
\text { refratário e rubor } & \text { da } & \text { rosácea } \\
\text { tratados } & \text { com } & & \text { injeções } \\
\text { intradérmicas de toxina botulínica. }\end{array}$ & $\begin{array}{l}\text { A injeção intradérmica de toxina botulínica } \\
\text { pode ser um tratamento eficaz para eritema } \\
\text { refratário e rubor da rosácea que merece um } \\
\text { estudo mais aprofundado em uma população } \\
\text { maior de pacientes. }\end{array}$ \\
\hline $\begin{array}{l}\text { Choi, J. E. } \\
\text { Werbel, T. } \\
\text { Wang, Z. } \\
\text { Wu, C. C. } \\
\text { Yaksh, T. L. } \\
\text { Di Nardo, A. }\end{array}$ & $\begin{array}{l}\text { Botulinum } \\
\text { toxin blocks } \\
\text { mast cells and } \\
\text { prevents } \\
\text { rosacea like } \\
\text { inflammation }\end{array}$ & 2019 & $\begin{array}{l}\text { Discutir o possível papel dos MCs } \\
\text { (Mast Cells - mastócitos) da pele } \\
\text { durante o processo da rosácea, e } \\
\text { uma perspectiva sobre sua inibição } \\
\text { para o tratamento da rosácea. }\end{array}$ & $\begin{array}{l}\text { Conclui-se que os MCs podem ser } \\
\text { importantes células imunes que conectam } \\
\text { imunidade inata, nervos e vasos sanguíneos } \\
\text { no desenvolvimento da rosácea, } \\
\text { independentemente dos subtipos. Porém, a } \\
\text { discussão desse mecanismo nas relações } \\
\text { complexas é ampla e limitada sendo } \\
\text { necessário então mais estudos. }\end{array}$ \\
\hline $\begin{array}{l}\text { Couto, L. } \\
\text { Ferreira, I. L. O. } \\
\text { da Silveira, M. L. } \\
\text { Steiner, D. }\end{array}$ & $\begin{array}{l}\text { Estudo } \\
\text { prospectivo } \\
\text { para tratamento } \\
\text { do rubor da } \\
\text { rosácea com } \\
\text { toxina } \\
\text { botulínica tipo } \\
\text { A }\end{array}$ & 2018 & $\begin{array}{l}\text { Demonstrar o efeito da toxina } \\
\text { botulínica na melhora do flushing } \\
\text { e eritema, em pacientes com } \\
\text { rosácea eritêmato-telangiectásica. }\end{array}$ & $\begin{array}{l}\text { Houve melhora dos sintomas e satisfação } \\
\text { das pacientes, sendo um tratamento de fácil } \\
\text { aplicação, com baixo índice de efeitos } \\
\text { adversos e duração prolongada do resultado. }\end{array}$ \\
\hline Chen, S. & $\begin{array}{l}\text { Clinical uses of } \\
\text { botulinum } \\
\text { neurotoxins: } \\
\text { current } \\
\text { indications, } \\
\text { limitations and } \\
\text { future } \\
\text { developments }\end{array}$ & 2012 & $\begin{array}{l}\text { Descrever o uso clínico atual de } \\
\text { BoNTs (toxina botulínica) e os } \\
\text { esforços para estender e otimizar } \\
\text { ainda mais seu valor em } \\
\text { intervenções terapêuticas, como a } \\
\text { rosácea. }\end{array}$ & $\begin{array}{l}\text { O futuro das BoNTs em aplicações médicas } \\
\text { é brilhante, ainda mais pesquisas são } \\
\text { necessárias para melhorar seus usos } \\
\text { médicos. Uma das áreas mais importantes é } \\
\text { testar o uso do BoNT recombinante como } \\
\text { agente terapêutico, uma vez que a } \\
\text { engenharia futura de novos BoNTs poderia } \\
\text { ser construída sobre um BoNT } \\
\text { recombinante. }\end{array}$ \\
\hline $\begin{array}{l}\text { Dayan, S. H. } \\
\text { Pritzker, R. N. } \\
\text { Arkins, J. P. }\end{array}$ & $\begin{array}{l}\text { A new } \\
\text { treatment } \\
\text { regimen for } \\
\text { rosacea: } \\
\text { onabotulinumt } \\
\text { oxinA }\end{array}$ & 2012 & $\begin{array}{l}\text { Analisar os efeitos da aplicação da } \\
\text { onabotulinumtoxinA na rosácea. }\end{array}$ & $\begin{array}{l}\text { As aplicações com a onabotulinumtoxinA } \\
\text { mostraram-se positivas e promissoras para } \\
\text { controle dos sintomas da rosácea. }\end{array}$ \\
\hline
\end{tabular}

Fonte: Autores (2021).

A rosácea é descrita por vários fatores, o mecanismo fisiopatológico do eritema persistente, por exemplo, é desconhecido, e não foi elucidado ainda sobre a duração e eficácia dos tratamentos sistêmicos a longo prazo para o controle do surto. Os medicamentos utilizados para controle da rosácea são administrados de forma paliativa e enquanto estão sendo utilizados os sintomas ficarão em remissão. No entanto, a possibilidade de ocorrer recidivas pode se manter por muitos anos, promovendo uma preocupação no que diz respeito a resistência a possíveis medicamentos e os danos cumulativos ao 
organismo quando utilizados de forma contínua. Tratamentos estéticos tópicos, como ácidos e fototerapia, podem produzir bons resultados clínicos, outro procedimento alternativo como a aplicação de toxina botulínica tem se mostrado muito promissor, porém existem poucas evidências científicas sobre seu mecanismo de ação, eficácia e durabilidade (Antonio et al., 2017).

Os tratamentos podem ser de ação tópica e oral, os recursos tópicos mais utilizados são gel de metronidazol, brimonidina, ácido azelaico, nicotinamida, adaptaleno, ivermectina e antibióticos, já os mais utilizados na administração oral são: a ivermectina, isotretinoína, os antibióticos (claritromicina, tetraciclina, azitromicina e eritromicina) (Two, Wu, Gallo, \& Hata, 2015a; Two, Wu, Gallo, \& Hata, 2015b).

Assim sendo, o critério final para a escolha de um tratamento é o benefício para a qualidade de vida do paciente. Em alguns casos é possível detectar uma baixa autoestima, podendo ser um gatilho para patologias mais graves como a depressão (Tan \& Berg, M., 2013; Feldman, Huang \& Huynh, 2014).

A toxina botulínica é muito conhecida pelos especialistas em medicina estética e tem ganhado cada vez mais lugar nas instituições especializadas em dermatologia. Diversos congressos internacionais de dermatologia e de medicina estética tem mostrado pesquisas sobre o uso da toxina no tratamento da rosácea. Essa toxina age combatendo também a oleosidade da face e ajudando a mitigar a acne na rosácea. Também diminui inflamações, muito embora seu uso para essa finalidade ainda esteja em estudos, mas os resultados têm demonstrado serem positivos (Dayan, Pritzker, \& Arkins, 2012).

\subsection{Rosácea}

A rosácea é uma doença vascular da pele, cuja causa é inflamatória e crônica, apresentando vários sintomas clínicos. No início é possível observar apenas o sinal de flushing, que corresponde às questões vasomotoras, porém os sintomas são proliferativos, apresentando telangiesctasias e foliculite e tendo muitas vezes associada a ação de microrganismos - o Demodex folliculorum (Antonio et al., 2017).

Inicialmente é caracterizada pelo eritema e calor desagradável, causado pela inflamação dos folículos capilares e vasos sanguíneos. À medida que a doença progride, o rubor é acompanhado por uma crista purulenta chamada pústula e pela formação de uma "teia de aranha" (representando um aumento nos vasos sanguíneos), além de uma crista vermelha e dolorosa chamada pápula. Sem tratamento, pode eventualmente causar o aparecimento de uma lesão elevada chamada "nódulo", deixando um "nariz de batata" no último estágio. Para um amador, pode parecer acne, mas existem diferenças: a rosácea, por exemplo, não produz manchas brancas ou pretas, a exposição moderada ao sol é benéfica para algumas pessoas com acne, não encontrada na rosácea. Na realidade, a exposição ao sol é a raiz deste problema de pele e pode ser uma alteração relacionada ao sol, pois raramente está presente em pacientes sem lesões na pele devido à exposição (Augustin, 2011).

As características secundárias da rosácea incluem sensação de queimação e coceira, dermatite seborréica e edema facial. Esse distúrbio de pele é facilmente identificável em pessoas de pele clara e, em casos graves, pode progredir para envolvimento ocular e rinofima. Apensar das características clínicas se sobreporem, o Comitê Nacional de Especialistas da Sociedade da Rosácea reconhece quatro principais subtipos de rosácea (Augustin, 2011; Awosika \& Oussedik, 2018).

A principal razão para afetar a face é devido à rica presença de glândulas sebáceas nessa área, a reatividade vascular da face ou anormalidades do sistema imunológico. Além da diversidade de sintomas clínicos, a etiologia e a fisiopatologia da rosácea permanecem desconhecidas, sem marcadores sorológicos ou histológicos (Augustin, 2011; Awosika \& Oussedik, 2018).

\subsection{Fisiopatologia}

Relacionado a causa das lesões, umas das principais teorias descritas e aceitas pelos pesquisadores é a desregulação 
do sistema imunológico. Em um organismo saudável é sabido que o sistema imune é uma das mais importantes barreiras de defesa contra agentes desconhecidos e com potencial alto de agressão, seja externo ou interno. Com secreção mediada pelos queratinócitos e outras células, como glândulas écrinas e sebóticas, um dos mecanismos envolvidos em tal sistema utilizam mediadores os peptídeos antimicrobianos (AMP's) ativados para atuarem protegendo o organismo contra agentes infecciosos, para que essa ativação ocorra de forma satisfatória um pró-peptídeo precisa ser clivado de forma enzimática. Os AMP's mais importantes no organismo humano são divididos em duas categorias - as defensinas e as catelicidinas (CRAMP) (Duman, Ersoy Evans, \& Atakan, 2014; Melnik, 2016).

Entre as duas categorias citadas a CRAMP apresenta uma maior importância para a rosácea, pois grandes quantidades da mesma foram encontradas em pacientes acometidos da patologia em questão (J. Y. Kim et al., 2014).

A clivagem para ativação da CRAMP é mediada por enzimas classificadas como proteases da serina, dentre as quais é possível destacar a calicreína KLK5, que a partir do momento de sua ativação passa a ser denominada catelecidina LL-37, esse mediador por sua vez está ligado de forma direta ao estímulo da cascata de inflamação, através da liberação de citocinas, quimiocinas e o fator de crescimento endotelial vascular (VEGF), estimulando por sua vez a angiogênese, desencadeando alterações teciduais de forma lesiva ao organismo. Na rosácea as duas formas enzimáticas foram encontradas com níveis aumentados, o que leva a um entendimento de uma resposta anormal do sistema imune inato ligado a fisiopatologia da rosácea. Para o aumento dos níveis da CRAMP duas vias podem ser ativadas, destacando uma delas que é dependente do estresse do retículo endoplasmático (SRE), um sinalizador de origem lipídica é responsável pelo aumento na produção de CRAMP - a esfingosina-1-fosfato. O SRE na rosácea é induzido através dos fatores desencadeantes, como excesso no consumo de álcool, temperaturas elevadas, alimentos muito condimentados e a radiação UV sem devida proteção, explicando o fato desses gatilhos influenciarem no desequilíbrio do sistema imunológico, tendo como consequência uma progressão da patologia (Abram, Silm, Maaroos, \& Oona, 2010; Steinhoff, Schauber, \& Leyden, 2013; Melnik, 2016).

A CRAMP está diretamente ligada ao KLK5, que por sua vez tem seu aumento correlacionado aos receptores transmembrânicos que compõe o sistema imune inato, dando destaque ao TRL2 - peptídeoglicanos e da MMP's metaloproteínas da matriz, com maior especificidade nas MMP-2 e MMP-9, responsáveis pela síntese e liberação de KLK5 e também com ação pró-inflamatória que agem como facilitador para a deterioração da barreira cutânea. No entanto, não é possível definir com precisão a participação de todos esses processos na etiopatogenia da rosácea (Del Rosso, 2012; Reinholz, Ruzicka, \& Schauber, 2012; J. Y. Kim et al., 2014; Okhovat, \& Armstrong, 2014; Two \& Del Rosso, 2014).

Considerando o infiltrado inflamatório presente na rosácea é possível destacar alguns subtipos celulares, como os linfócitos $\mathrm{T}$ e mastócitos, porém já é comprovado a presença de outras variações celulares dependendo do grau da patologia apresentada. Os mastócitos apresentam na fisiopatologia da rosácea uma ação direta na mediação da inflamação com as manifestações clínicas. Ficando então explicito a participação das células e da CRAMP no aumento e progressão da patologia (Del Rosso, 2012; Two \& Del Rosso, 2014; Buhl et al., 2015).

Outros fatores de suma importância na etipatologia da rosácea são o desequilibro vascular presente e a desregulação da barreira cutânea. Uma das manifestações clínicas mais comum na rosácea é a vasodilatação de forma exacerbada dos vasos sanguíneos cutâneos mais superficiais da face. A explicação de tal desequilíbrio pode estar associada ao aumento na quantidade de VEGF, responsável pelo aumento da angiogênese, mas também por alterações como aparecimento das telangiectasias, aumento do pH, o aumento da permeabilidade capilar, causando uma desidratação nas regiões afetadas. Esse conjunto de alterações contribuem para a diminuição na barreira protetora, tornando a região cutânea susceptível a agentes agressores, e eventos de maior irritação da pele (Del Rosso, 2012).

É observada na rosácea uma variedade de formas nas manifestações clínicas, sendo então subdividas em primárias e secundárias. Incluindo nos sinais e sintomas primários eritema transitório, eritema persistente, pápulas eritematosas e 
telangiectasias. Já nas manifestações secundárias é possível encontrar placas eritematosas, edema facial, aparência desidratada, sensação de ardência e comprometimento ocular, como prurido, ardor e inflamação (Wilkin et al., 2004).

Para a realização do diagnóstico da rosácea são observadas apenas as manifestações de forma clínica, os testes laboratoriais ainda são escassos para auxiliar no diagnóstico (Weinkle, Doktor, \& Emer, 2015).

\subsection{Classificação}

A classificação da rosácea foi estruturada em 2002 (Quadro 1), pela National Rosacea Society (NRS), onde foi apresentado um novo quadro de classificação, tendo como base o conhecimento científico existente sobre a patologia e suas características morfológicas. Sendo então, nomeados 4 grupos (Wilkin et al., 2004).

A rosácea eritemato-telangiectásica (RET) é classificada como subtipo 1, conhecida também como rosácea vascular, tem como principais características eritema facial podendo ou não ser transitório, telangiectasias, sensibilidade cutânea, sensação de ardência e calor. Atinge mais comumente a região central da face, porém não é observado excesso de oleosidade como ocorre em outros subtipos. Os sinais e sintomas podem ser controlados, caso contrário é provável que um agravamento da doença ocorra por falta de cuidados profiláticos. Na histopatologia é possível caracterizar o subtipo 1 através da presença de vênulas e capilares de forma dilatada e com estrutura alterada nas regiões mais superficiais da pele, no processo inflamatório é observado células do sistema de defesa, como plasmócitos, mastócitos e linfócitos, esses últimos em maior quantidade (Wilkin et al., 2004; Cribier, 2013).

O subtipo 2, classificado como rosácea papulopustular, é a manifestação mais encontrada entre a população acometida com a disfunção, com característica inflamatória, conta com a presença de pápulas e pústulas, caracterizando comprometimento sebáceo nas regiões, podendo ser confundida com a acne vulgar, sendo muito importante a ausência de comedões para a caracterização assertiva da patologia (Wilkin et al., 2004). Concordante com o subtipo 1 a maior prevalência continua sendo a região central da face, tendo destaque para a região do malar com maior índice inflamatório. As manifestações presentes são as mesmas apresentadas na RET, porém com maior intensidade e maior frequência de eventos ativos. Na análise histopatológica é possível observar um infiltrado de células mais intenso, rico em linfócitos e plasmócitos, mas também caracterizado pela presença dos neutrófilos, dos eosinófilos e microrganismos como o ácaro D. folliculorum. Devido a presença de pápulas e pústulas algumas imagens da histopatologia podem ser confundidas com a acne, porém na rosácea não é observado a presença dos comedões (Cribier, 2013).

A Rosácea Fimatosa é classificada como o subtipo 3, sendo considerado o estágio mais grave da síndrome, tendo como uma das principais características a hiperplasia das glândulas sebáceas, resultando em um número elevado de pápulas com ligações entre si, com cor amarelada que se pressionada libera uma substância de textura pastosa, composta por células e microrganismos, como por exemplo o D. folliculorum. O maior acometimento são as regiões convexas centrais da face (Wilkin et al., 2004).

O subtipo 4 chamado de rosácea ocular tem como principal característica o comprometimento dos olhos. Estima-se que de 50 a $70 \%$ dos indivíduos portadores da rosácea contenham algum comprometimento ocular. Em geral, 20\% dos casos as lesões oculares se manifestam antes mesmo das lesões cutâneas, resultando muitas vezes em um diagnóstico equivocado devido à falta de manifestações mais específicas, relacionadas à pele (Wilkin et al., 2004).

\subsection{Tratamento}

A rosácea é uma patologia de origem multifatorial, um dos possíveis fatores desencadeantes é a presença de microrganismos considerados agentes infecciosos estando então, diretamente ligados e etipatogenia da disfunção. Os mais frequentes encontrados nas regiões afetadas são - Demodex folliculorum, Helicobacter pylori, Bacillus oleronius e 
Staphylococcus epidermidis. O S. epidermidis é encontrado em grande quantidade na região cutânea do organismo humano, sendo responsável pela proteção contra entrada de agentes patogênicos. É sugerido então que na rosácea uma anormalidade afete tais microrganismos inibindo sua capacidade de proteção e contribuindo para a síntese de ativos que influenciam na ativação do sistema imune e da cascata inflamatória, ativando consequentemente a KLK5 e a CRAMP. Outro microrganismo em destaque é o $D$. folliculorum classificado com um ácaro se encontra nas glândulas sebáceas da região facial, em indivíduos portadores da rosácea esse ácaro está presente em maior número, podendo ser plicado pela ligação direta da patologia com as hiperplasias das glândulas sebáceas (Two, et al., 2015a; Two, et al., 2015b).

Dessa forma a utilização de princípios ativos de ação sistêmica, que tem como objetivo combater tais microrganismos e de administração oral é uma opção utilizada pelos profissionais, na tentativa de controlar os sinais e sintomas da disfunção cutânea. Para utilização sistêmica os medicamentos mais utilizados são os antibióticos, a isotretinoína e o metronidazol. A tetraciclina é a principal terapêutica sistêmica utilizada para controle dos sinais e sintomas da rosácea, seu mecanismo de ação atua através da inibição das MMPs, redução da atividade da KLK5 e consequente diminuição dos infiltrados de células de defesa. Porém, o uso contínuo desencadeia efeitos indesejáveis ao organismo sendo necessária a busca de outras terapias para regressão das manifestações clínicas presentes na rosácea. A isotretinoína é indicada em casos mais graves da rosácea, onde as glândulas sebáceas se mostram comprometidas, com sua capacidade de diminuir o tamanho das glândulas o ativo é utilizado para tal fim, porém suas reações adversas colocam em dúvida sua permanência no rol de medicamentos prescritos para a patologia cutânea. O metronidazol de administração oral vem sendo descontinuado devido ao risco de neuropatias e convulsões (Weinkle et al., 2015; Lanoue \& Goldenberg, 2015).

Existe também a possiblidade de controlar os sinais e sintomas através de ativos de administração tópica, promovendo uma ação local. Entre os fármacos mais utilizados é possível destacar o Metronidazol, com propriedades antibacterianas e antiinflamatórias que auxiliam na regressão do eritema, pápulas e pústulas, porém pode apresentar quadros de irritação no local da aplicação (Draelos, Elewski, Staedtler, \& Havlickova, 2013; Korting, \& Schöllmann, 2009).

O ácido azelaico atua como uma substância antibacteriana, anti-inflamatória e também antioxidante, em quadros mais leves da rosácea, podendo ter como efeitos colaterais irritação, parestesias e prurido nas áreas aplicadas. Outro ativo utilizado para atenuar o eritema presente na rosácea é a Brimonidina, um agonista do receptor adrenérgico, atuando como um vasoconstritor. No entanto, seu uso deve ser realizado com muita precaução, principalmente em pacientes que apresentem depressão, insuficiência arterial, coronário ou cerebral, hipotensão ortostática, doença cardiovascular em geral, pois aumenta o risco de ocorrer um agravamento no quadro de insuficiência vascular em portadores de tais patologias (Draelos et al., 2013; Fowler et al., 2013; Moore et al., 2014).

Autores acrescentam que há outro tratamento, sendo que o mesmo inclui o uso de outros tipos de antibióticos orais, como os macrolídeos, como a claritromicina, azitromicina e a eritromicina (Draelos et al., 2013).

A rosácea granulomatosa responde muito bem à administração sistêmica de alguns fármacos, no entanto, a tendência para recaídas pode durar anos. Alguns parecem exigir antibioticoterapia sistêmica a longo prazo para manter a remissão, enquanto outros evitam fatores desencadeantes e progridem bem com medicamentos tópicos, como o gel de Metronidazol. Os antibióticos atuam como agentes anti-inflamatórios, reduzindo a migração de leucócitos e a fagocitose. Sua eficácia no tratamento da rosácea foi confirmada com $80 \%$ de bons resultados com o uso de $250 \mathrm{mg}$ de tetraciclina duas vezes ao dia. Porém muitos efeitos colaterais, como lesões hepáticas e eventos no trato gastrointestinal, foram detectados, assim como resistência aos medicamentos (Korting, \& Schöllmann, 2009; Schaller et al., 2017).

\subsection{Tratamentos alternativos}

Com o intuito de diminuir os efeitos colaterais desencadeados pelos medicamentos tradicionais, novos estudos foram 
realizados a fim de encontrar um método mais seguro para controlar os sinais e sintomas da rosácea. A toxina botulínica então, foi testada para tal finalidade. Estudos revelaram que a ação da toxina botulínica da tipo A no bloqueio dos receptores présinápticos de acetilcolina promoveram uma regressão na vascularização excessiva das regiões acometidas pela patologia, pois é sabido que o neuromediador tem uma ação direta na vasodilatação cutânea. Nos subtipos II e III da rosácea a ação da toxina tem outro papel fundamental, a atuação nas glândulas sebáceas, pois as glândulas também dependem da acetilcolina para ter sua produção de sebo ativada, com a inibição na liberação do neuromediador, ocorre uma atrofia das glândulas diminuindo sua ação. Para portadores da rosácea isso é de extrema valia, já que o tratamento é apenas o controle dos sinais e sintomas, diminuindo ao máximo os efeitos sistêmicos para o organismo (Chen, 2012; Dayan et al., 2012; Bloom, Payongayong, Mourin, \& Goldberg, 2015; Park et al., 2015; Choi, 2019).

A capacidade de oferecer um tratamento que leva apenas alguns minutos e pode ser realizada três a quatro vezes por ano, evitando a necessidade de vários tratamentos a laser, medicamentos sistêmicos ou tratamentos tópicos diários, seria uma alternativa desejável para o paciente e o médico. A rosácea que afeta o rosto pode ser uma grande perturbação na vida profissional, social e familiar. Pesquisas da Sociedade Nacional da Rosácea indicam que mais de $76 \%$ dos pacientes com rosácea acham que a condição diminui sua autoconfiança e autoestima, com $41 \%$ relatando que faz com que evitem o contato público ou cancelem compromissos sociais. As ações responsáveis pela eficácia da toxina botulínica na redução dos sintomas da rosácea são lógicas, mas ainda não estão claramente delineadas. Talvez por inibir a liberação de VIP e ACh, a toxina botulínica esteja inibindo os efeitos de dois dos peptídeos neurogênicos conhecidos, ligados à inflamação e vasodilatação na rosácea, ou talvez ainda estejam sendo identificados os mecanismos exatos pelos quais a toxina botulínica impede a liberação de um dos numerosos outros neuropeptídeos envolvidos na atividade sebácea, homeostase vascular e inflamação (Couto, L., Ferreira, da Silveira, \& Steiner, 2018).

Outra opção de tratamento, também comprovada, eficaz e segura para rosácea é o uso de tecnologia baseada em luz. O LIP (Luz Intensa Pulsada) é uma técnica criada para tratar lesões em vasos sanguíneos e lesões pigmentadas, além de outros usos, como retirada de pelos e fotorrejuvenescimento. Ele pode gerar pulsos de sincronização simples e/ou múltiplos e alterar a duração dos disparos, tornando-a uma ferramenta muito versátil. O tratamento otimiza o colágeno e as fibras elásticas na derme. Isso ocorre devido à absorção seletiva da luz pela água do tecido, o que aumenta a condução de calor ao redor do colágeno e aumenta a produção de colágeno. Há também um aumento na produção de fibroblastos devido ao efeito fototérmico, o que explica os resultados apresentados por pacientes com menos de 40 anos (Marques, Moran, Speyer, Azevedo, \& Cohen, 2016; Trindade Neto, Rocha, Lima, Nunes, \& Silva, 2006; Chamusca, Reis, Lemaire, \& Medrado, 2012).

\section{Considerações Finais}

Os estudos mostram um futuro promissor para os tratamentos alternativos, o fator de proporcionar ao paciente um protocolo que promova maior segurança, ou seja, um índice menor de efeitos colaterais e com um resultado eficaz, vem ganhando espaço nos consultórios profissionais, como por exemplo, o uso da toxina botulínica A. Em todos os trabalhos de pesquisas empíricas analisados, os autores demonstraram otimismo em relação ao método de aplicação e também aos resultados.

Entretanto, há um consenso acerca dos estudos sobre o uso na rosácea, afirmando a necessidade de maiores incentivos, pois ainda há um descompasso no número de estudos, na atenção dada pelos especialistas em relação a real importância dessa toxina para terapia.

Em relação ao método de aplicação, não há um só método, mas vários. Entretanto, essa variação não deve operar de forma arbitrária, pois a realidade de cada caso clínico deve orientar a construção da melhor forma de aplicação. Neste trabalho, foram analisadas algumas pesquisas com o uso da toxina botulínica na rosácea e ficou claro que os autores não fizeram uso da 
forma idêntica, usando a mesma dosagem, o mesmo planejamento de aplicação, muito embora tenha sido deveras similar.

A forma de aplicação da toxina botulínica na rosácea deve obedecer a dois imperativos metodológicos básicos em todo procedimento clínico: os conhecimentos padrões sobre a toxina, sobre seu uso de uma forma geral (dosagem adequada, pontos de aplicação, formas de aplicação, etc) e as especificidades de cada caso clínico.

O desejo de proporcionar ao paciente protocolos que promovam segurança e eficácia é algo que vem ganhando espaço principalmente no que diz respeito ao uso da toxina botulínica. Nesse contexto, trabalhos futuros contemplando o estudo da toxina botulínica associada ao tratamento e acompanhamento da rosácea e outras doenças de pele devem ser incentivados, para aproveitar todo o potencial terapêutico dessa substância.

\section{Referências}

Abram, K., Silm, H., Maaroos, H. I., \& Oona, M. (2010). Risk factors associated with rosacea. Journal of the European Academy of Dermatology and Venereology, 24(5), 565-571.

Antonio, C. R., Antonio, J. R., Trídico, L. A., \& Fernandes, T. É. A. (2017). Tratamento de Rosácea com Toxina Botulínica. Surgical \& Cosmetic Dermatology, 10(3), 36-39.

Augustin, M., Herberger, K., Hintzen, S., Heigel, H., Franzke, N., \& Schäfer, I. (2011). Prevalence of skin lesions and need for treatment in a cohort of 90880 workers. British Journal of Dermatology, 165(4), 865-873.

Awosika, O., \& Oussedik, E. (2018). Genetic predisposition to rosacea. Dermatologic Clinics, 36(2), 87-92.

Bloom, B. S., Payongayong, L., Mourin, A., \& Goldberg, D. J. (2015). Impact of intradermal abobotulinumtoxinA on facial erythema of rosacea. Dermatologic Surgery, 41, S9-S16.

Buhl, T., Sulk, M., Nowak, P., Buddenkotte, J., McDonald, I., Aubert, J., \& Voegel, J. J. (2015). Molecular and morphological characterization of inflammatory infiltrate in rosacea reveals activation of Th1/Th17 pathways. Journal of Investigative Dermatology, 135(9), 2198-2208.

Choi, J. E., Werbel, T., Wang, Z., Wu, C. C., Yaksh, T. L., \& Di Nardo, A. (2019). Botulinum toxin blocks mast cells and prevents rosacea like inflammation. Journal of Dermatological Science, 93(1), 58-64.

Couto, L., Ferreira, I. L. O., da Silveira, M. L., \& Steiner, D. (2018). Estudo prospectivo para tratamento do rubor da rosácea com toxina botulínica tipo A. Surgical \& Cosmetic Dermatology, 10(2), 121-126.

Chamusca, F. V., Reis, S. R. A., Lemaire, D., \& Medrado, A. P. (2012). Mediadores do efeito sistêmico do processo inflamatório e terapias fotobiomoduladoras: uma revisão de literatura. Revista de Ciências Médicas e Biológicas, 11(1), 70-78

Chen, S. (2012). Clinical uses of botulinum neurotoxins: current indications, limitations and future developments. Toxins, 4(10), 913-939.

Crawford, G. H., Pelle, M. T., \& James, W. D. (2004). Rosacea: I. Etiology, pathogenesis, and subtype classification. Journal of the American Academy of Dermatology, 51(3), 327-341.

Cribier, B. (2013). Rosacea under the microscope: characteristic histological findings. Journal of the European Academy of Dermatology and Venereology, 27(11), 1336-1343.

Dayan, S. H., Pritzker, R. N., \& Arkins, J. P. (2012). A new treatment regimen for rosacea: onabotulinumtoxinA. Journal of Drugs in Dermatology, 11(12), e76-e79.

Del Rosso, J. Q. (2012). Advances in understanding and managing rosacea: part 1: connecting the dots between pathophysiological mechanisms and common clinical features of rosacea with emphasis on vascular changes and facial erythema. The Journal of Clinical and Aesthetic Dermatology, 5(3), 16-25.

Di Matteo, M. C., Stefano, P. C., Cirio, A., López, B., Centeno, M., Bocian, M., \& Cervini, A. B. (2019). Rosácea oculocutánea en un niño. Arquivos Argentinos de Pediatria, 170-172.

Draelos, Z. D., Elewski, B., Staedtler, G., \& Havlickova, B. (2013). Azelaic acid foam 15\% in the treatment of papulopustular rosacea: a randomized, doubleblind, vehicle-controlled study. Cutis, 92(6), 306-317.

Duman, N., Ersoy Evans, S., \& Atakan, N. (2014). Rosacea and cardiovascular risk factors: a case control study. Journal of the European Academy of Dermatology and Venereology: JEADV, 28(9), 1165-1169.

Feldman, S. R., Huang, W. W., \& Huynh, T. T. (2014). Current drug therapies for rosacea: a chronic vascular and inflammatory skin disease. Journal of Managed Care Pharmacy, 20(6), 623-629.

Fowler Jr, J., Jackson, M., Moore, A., Jarratt, M., Jones, T., Meadows, K., \& Leoni, M. (2013). Efficacy and safety of once-daily topical brimonidine tartrate gel $0.5 \%$ for the treatment of moderate to severe facial erythema of rosacea: results of two randomized, double-blind, and vehicle-controlled pivotal studies. Journal of Drugs in Dermatology: JDD, 12(6), 650-656. 
Research, Society and Development, v. 10, n. 2, e55610212780, 2021

(CC BY 4.0) | ISSN 2525-3409 | DOI: http://dx.doi.org/10.33448/rsd-v10i2.12780

Kim, J. Y., Kim, Y. J., Lim, B. J., Sohn, H. J., Shin, D., \& Oh, S. H. (2014). Increased expression of cathelicidin by direct activation of protease-activated receptor 2: possible implications on the pathogenesis of rosacea. Yonsei Medical Journal, 55(6), 1648-1655.

Korting, H. C., \& Schöllmann, C. (2009). Current topical and systemic approaches to treatment of rosacea. Journal of the European Academy of Dermatology and Venereology, 23(8), 876-882.

Lanoue, J., \& Goldenberg, G. (2015). Therapies to improve the cosmetic symptoms of rosacea. Cutis, 96(1), 19-26.

Marques, R. Z. S., Moran, D. K. S., Speyer, C., Azevedo, L. C. M., \& Cohen, S. (2016). Tratamento de rosácea com duas faixas de comprimento de onda de luz intensa pulsada num mesmo disparo. Surgical \& Cosmetic Dermatology, 8(2), 128-132.

Melnik, B. C. (2016). Rosacea: the blessing of the Celts-an approach to pathogenesis through translational research. Acta Dermato-Venereologica, 96(2), 147156.

Moore, A., Kempers, S., Murakawa, G., Weiss, J., Tauscher, A., Swinyer, L., \& Leoni, M. (2014). Long-term safety and efficacy of once-daily topical brimonidine tartrate gel $0.5 \%$ for the treatment of moderate to severe facial erythema of rosacea: results of a 1-year open-label study. Journal of Drugs in Dermatology: JDD, 13(1), 56-61.

Moustafa, F., Hopkinson, D., Huang, K. E., \& Feldman, S. (2015). Prevalence of rosacea in community settings. Journal of Cutaneous Medicine and Surgery, $19(2), 149-152$.

Okhovat, J. P., \& Armstrong, A. W. (2014). Updates in rosacea: epidemiology, risk factors, and management strategies. Current Dermatology Reports, 3(1), 23-28.

Park, K. Y., Hyun, M. Y., Jeong, S. Y., Kim, B. J., Kim, M. N., \& Hong, C. K. (2015). Botulinum toxin for the treatment of refractory erythema and flushing of rosacea. Dermatology, 230(4), 299-301.

Pereira A. S., Shitsuka, D. M., Parreira, F. J., \& Shitsuka, R. (2018). Metodologia da pesquisa científica. UFSM. https://repositorio.ufsm.br/bitstream/ handle/1/15824/Lic_Computacao_Metodologia-Pesquisa-Cientifica.pdf?sequence=1.

Reinholz, M., Ruzicka, T., \& Schauber, J. (2012). Cathelicidin LL-37: an antimicrobial peptide with a role in inflammatory skin disease. Annals of dermatology, 24(2), 126-135.

Schaller, M., Almeida, L. M. C., Bewley, A., Cribier, B., Dlova, N. C., Kautz, G., \& Thiboutot, D. (2017). Rosacea treatment update: recommendations from the global ROSacea COnsensus (ROSCO) panel. British Journal of Dermatology, 176(2), 465-471.

Steinhoff, M., Schauber, J., \& Leyden, J. J. (2013). New insights into rosacea pathophysiology: a review of recent findings. Journal of the American Academy of Dermatology, 69(6), S15-S26.

Steinhoff, M., Schmelz, M., \& Schauber, J. (2016). Facial erythema of rosacea-aetiology, different pathophysiologies and treatment options. Acta dermatovenereologica, 96(5), 579-589.

Tan, J., \& Berg, M. (2013). Rosacea: current state of epidemiology. Journal of the American Academy of Dermatology, 69(6), S27-S35.

Trindade Neto, P. B. D., Rocha, K. B. F., Lima, J. B. D., Nunes, J. C. S., \& Silva, A. C. D. O. (2006). Rosácea granulomatosa: relato de caso-enfoque terapêutico. Anais Brasileiros de Dermatologia, 81, S320-S323.

Two, A. M., \& Del Rosso, J. Q. (2014). Kallikrein 5-mediated inflammation in rosacea: clinically relevant correlations with acute and chronic manifestations in rosacea and how individual treatments may provide therapeutic benefit. The Journal of Clinical and Aesthetic Dermatology, 7(1), 20-25.

Two, A. M., Wu, W., Gallo, R. L., \& Hata, T. R. (2015a). Rosacea: part I. Introduction, categorization, histology, pathogenesis, and risk factors. Journal of the American Academy of Dermatology, 72(5), 749-758.

Two, A. M., Wu, W., Gallo, R. L., \& Hata, T. R. (2015b). Rosacea: part II. Topical and systemic therapies in the treatment of rosacea. Journal of the American Academy of Dermatology, 72(5), 761-770.

Weinkle, A. P., Doktor, V., \& Emer, J. (2015). Update on the management of rosacea. Clinical, Cosmetic and Investigational Dermatology, 8, $159-177$.

Wilkin, J., Dahl, M., Detmar, M., Drake, L., Liang, M. H., Odom, R., \& Powell, F. (2004). Standard grading system for rosacea: report of the National Rosacea Society Expert Committee on the classification and staging of rosacea. Journal of the American Academy of Dermatology, 50(6), 907-912. 